\title{
Níveis dietéticos de proteína e gordura e parâmetros bioquímicos, hematológicos e empenamento em frangos de corte estressados pelo calor ${ }^{1}$
}

\author{
Christine Laganá2 ${ }^{2}$ Andréa Machado Leal Ribeiro ${ }^{3}$, Félix Hilario Diaz González ${ }^{4}$, Luciana de \\ Almeida Lacerda ${ }^{4}$, Lílian Ribeiro Kratz ${ }^{3}$, Patrícia Rick Barbosa ${ }^{4}$ \\ ${ }^{1}$ Parte da tese apresentada pela primeira autora à Universidade Federal do Rio Grande do Sul como um dos requisitos para obtenção do \\ título de Doutor em Zootecnia. \\ 2 APTA/PRDTA Leste Paulista, Caixa Postal 01, CEP: 13910-000, Monte Alegre do Sul/SP. \\ ${ }^{3}$ Laboratório de Ensino Zootécnico/UFRGS - CP 776, CEP: 91540-000, Porto Alegre/RS. \\ ${ }^{4}$ Departamento de Patologia Clínica Veterinária, LACVet, Faculdade de Veterinária/UFRGS - Av. Bento Gonçalves, 9090, CEP: 91540-000, \\ Porto Alegre/RS.
}

RESUMO - Avaliaram-se dietas com diferentes níveis de PB e gordura e seus efeitos sobre o empenamento e os parâmetros hematológicos e bioquímicos de frangos de corte submetidos a estresse cíclico por calor (EPC) desde os 21 dias ou em ambiente termoneutro (ATN). Foi adotado esquema fatorial 2 × $2+2$, com dois ambientes - ATN $\left(21-25^{\circ} \mathrm{C}\right.$ e UR $73 \%)$ e EPC $\left(25-32^{\circ} \mathrm{C}\right.$ e UR $\left.65 \%\right)$ e duas dietas (D) - controle (2,4\% gordura e 19,5\% proteína) e verão (DV) (4,0\% de gordura e 18,5\% de proteína com suplementação de Lys e Met + Cys no nível da dieta controle). No ambiente ATN, foram elaboradas outras duas dietas, com quantidade equalizada de ração em relação ao EPC, para ambas as dietas. Foram realizadas análises bioquímicas e hematológicas em seis aves/tratamento, aos 42 dias de idade, e pesados a bursa e baço; em 288 aves foi avaliado o rendimento de penas (RP). A DV para frangos de corte em EPC foi capaz de amenizar parte das alterações observadas no calor, resultando em melhor peso relativo de bursa, menor número de leucócitos totais e menor relação heterófilo/ linfócito. Ambiente e dietas não alteraram os parâmetros bioquímicos séricos. Aves com consumo à vontade no ATN apresentaram RP 15\% maior que aves no EPC, embora a restrição alimentar tenha diminuído o RP para as aves com consumo equalizado. As dietas não afetaram o RP. Os dados sugerem que tanto o EPC quanto a restrição alimentar são fatores aditivos em diminuir produção de penas.

Palavras-chave: empenamento, estresse por calor, hematologia, gordura, proteína

\section{Dietary levels of protein and fat on biochemical and hematological parameters and on feathering in heat stressed broilers}

\begin{abstract}
The objective was to evaluate diets with different levels of CP and fat, and their effect on feathering and hematological and biochemical parameters of broilers submitted to cyclic heat stress (HS) since $21 \mathrm{~d}$ of age or in thermoneutral environment (TN). A factorial $2 \times 2+2$ was used, with two environments-TN $\left(21-25^{\circ} \mathrm{C}\right.$ and $\left.\mathrm{RH} 73 \%\right)$ and $\mathrm{HS}\left(25-32^{\circ} \mathrm{C}\right.$ and RH 65\%), and two diets (D) - control (2.4\% fat and 19.5\%CP) and summer (SD) (4.0\% fat and 18.5\% CP with Lys and Met + Cys supplemented at the control diet level). On TN environment, two more diets were formulates, with the amount equalized (pair feed) of ration in relation to HS, for both diet. Biochemistry and hematological analyses were carried out in six birds/ treatment, at 42 days-old, and bursa and spleen weighed and feather yield (FY) was evaluated in 288 birds. The DV for broiler in EPC was capable to attenuate part of the alterations observed in the heat, resulting in better relative weight of bursa, small number of total leukocytes and smaller heterophils/lynphocytes relationship. Environment and diets did not change biochemistry serum parameters. Birds with ad libitum intake in the ATN showed FY 15\% greater that birds in the HS, even so the feed restriction decreased RP for the birds with pair feed intake. Diets did not influence FY. Data suggests that either HS or feed intake restriction are additive factors that decrease feather production.
\end{abstract}

Key Words: fat, feathering, heat stress, hematology, protein

\section{Introdução}

A temperatura ambiente pode ser considerada o fator físico de maior efeito no desempenho de frangos de corte, com grande influência no consumo de ração (Teeter et al.,
1984) e no ganho de peso e na conversão alimentar. Animais sob estresse apresentam modificações metabólicas expressas por alterações bioquímicas e hematológicas.

Somado a esse fato, Thaxton \& Siegel (1982) e Miller \& Qureshi (1991) demonstraram que galinhas quando expostas 
a temperaturas elevadas intermitentes, variando de 32,2 a $43^{\circ} \mathrm{C}$, por períodos curtos, ou ciclos de altas temperaturas constantes, apresentaram metabolismo protéico alterado e resposta imune reduzida, expressa pela involução do sistema linfático, incluindo atrofia do timo, da bolsa de Fabrício, do baço e pâncreas.

Em geral, os quadros de estresse manifestam-se com diferentes graus de involução do sistema linforreticular. A liberação de corticosterona pode ocasionar a involução do tecido linfóide (timo, bursa de Fabrício e baço) e a supressão da imunidade humoral e celular (Rosales et al., 1989).

O peso proporcional e a morfologia dos órgãos linfóides primários são adotados para avaliar a resposta de casos de estresse (Revidatti et al., 2002). O número de leucócitos no sangue dos frangos varia de 12.000 a 30.000 , porém pode variar em função do sexo, da idade, das condições de estresse e de doenças. A contagem diferencial de células no sangue tem mostrado que, do total de leucócitos, 60 a $65 \%$ são linfócitos, 25 a 30\% são heterófilos, 2\% são eosinófilos, 1,7\% são basófilos e $10 \%$ são monócitos. Os achados de contagem diferencial mostram que a proporção normal de heterófilos: linfócitos (H/L) está em torno de 1:2. Entretanto, essa relação aumenta quando os frangos são submetidos a condições de estresse, que aumenta a quantidade de heterófilos na circulação (Macari \& Luquetti, 2002).

Com relação aos parâmetros de desempenho, Dale \& Fuller (1980) observaram que os efeitos adversos de altas temperaturas foram reduzidos quando $27,5 \%$ da energia metabolizável (EM) da dieta foi suprida por gordura. Os autores constataram que a taxa de crescimento de aves submetidas a estresse cíclico pelo calor melhorou em decorrência da adição de gordura à ração. Porém, o mesmo não aconteceu para aves submetidas a estresse crônico.

O empenamento aliado à temperatura ambiente pode interferir no metabolismo energético das aves. Peguri \& Coon (1993) observaram que a exigência de energia metabolizável para mantença nas aves em ambiente de temperatura fria $\left(12,8^{\circ} \mathrm{C}\right)$, com $0 \%$ de penas, foi duas vezes maior que as necessidades das aves em ambiente de alta temperatura $\left(33,9^{\circ} \mathrm{C}\right)$ e $0 \%$ de penas. Segundo Horst \& Mathur (1994), sob condições de estresse por calor, a redução na intensidade do empenamento pode aumentar a temperatura crítica superior das aves.

Objetivou-se com este estudo avaliar o efeito de dietas com diferentes níveis de gordura (4,0 vs 2,4\%) e PB (18,5 vs 19,5\%) no empenamento, na bioquímica sérica e nos parâmetros hematológicos e morfológicos de frangos de corte submetidos a estresse cíclico por calor (EPC) $\left(25-32^{\circ} \mathrm{C}\right)$, no período de 21 a 42 dias, e verificar o efeito direto do EPC no consumo equalizado das aves.

\section{Material e Métodos}

Foram utilizados 288 pintos machos, Ross, de 21 dias de idade, distribuídos em blocos de três categorias de peso ( 700 a 770 g, 771 a 870 g e 871 a 940g), em esquema fatorial $2 \times 2+2$ : dois ambientes termoneutros - ATN $\left(21-25^{\circ} \mathrm{C}\right.$ e UR $73 \%)$ e EPC $\left(25-32^{\circ} \mathrm{C}\right.$ e UR $\left.65 \%\right)$ e dois tipos de dieta controle (2,4\% gordura e $19,5 \%$ proteína) e verão (4,0\% de gordura e 18,5\% de proteína com suplementação de lisina e metionina + cistina no nível da dieta controle), com seis repetições de oito aves cada. No ATN, foram elaboradas mais duas dietas, fornecidas às aves submetidas à restrição alimentar (consumo equalizado), mantendo-se o mesmo consumo das aves em EPC, para ambos os tipos de ração.

As dietas foram formuladas (Tabela 1) conforme a seguinte distribuição: controle-EPC1; dieta verão-EPC2; dieta controle, à vontade - ATN1; dieta verão, à vontade ATN2; dieta controle, consumo equalizado com EPC1 ATN3; dieta verão, consumo equalizado com EPC2 - ATN4. Para equalizar o consumo das dietas ATN3 e ATN4 com EPC1 e EPC2, calculou-se, diariamente, o consumo de EPC1 e EPC2 e a quantidade de ração consumida foi ofertada nos dois primeiros tratamentos no dia seguinte.

Foi considerado estresse cíclico por calor o período de 12 horas de temperatura a $25^{\circ} \mathrm{C}$, três horas de 25 a $32^{\circ} \mathrm{C}$, seis horas a $32^{\circ} \mathrm{C}$ e três horas de 32 a $25^{\circ} \mathrm{C}$, diariamente, ao passo que ao ambiente termoneutro referiam-se as temperaturas diárias na faixa de 21 a $25^{\circ} \mathrm{C}$. A umidade relativa média do ar ficou em torno de $65 \%$ no EPC e no ATN, de 65 a $81 \%$, no período de 28 a 42 dias, alcançando média de $73 \%$.

O abate de seis aves por tratamento foi realizado aos 42 dias, na seguinte seqüência: pesagem das aves, morte por deslocamento cervical, sangria, escaldagem, depenamento e retirada dos órgãos linfóides.

As aves foram pesadas antes e depois do depenamento, calculando-se o peso relativo de penas por meio da divisão do peso absoluto pelo peso vivo da ave.

Durante a sangria, $10 \mathrm{~mL}$ de sangue foram coletados da veia jugular, dos quais $5 \mathrm{~mL}$ foram mantidos em tubo a vácuo com anticoagulante EDTA a 10\%, para análises hematológicas, e $5 \mathrm{~mL}$ em tubo a vácuo sem anticoagulante, para análises bioquímicas.

Os parâmetros sangüíneos determinados foram: hematócrito, concentração de hemoglobina, contagem total e diferencial de leucócitos (heterófilos, linfócitos, eosinófilos, basófilos e monócitos), avaliação da morfologia celular e relação heterófilos/linfócitos (H/L). Do perfil bioquímico sérico foram obtidas proteínas totais, glicose, fructosamina, albumina e globulinas. O hematócrito foi realizado por microcentrifugação. A contagem total e dife- 
Tabela 1 - Composição em ingredientes e nutricional das dietas experimentais

Table 1 - Ingredients and nutritional composition of the experimental diets

\begin{tabular}{|c|c|c|}
\hline $\begin{array}{l}\text { Ingrediente } \\
\text { Ingredient }\end{array}$ & $\begin{array}{l}\text { Dieta controle }{ }^{1} \\
\text { Control diet }\end{array}$ & $\begin{array}{l}\text { Dieta verão } \\
\text { Summer diet }\end{array}$ \\
\hline $\begin{array}{l}\text { Milho } \\
\text { Corn }\end{array}$ & 64,1 & 61,12 \\
\hline $\begin{array}{l}\text { Farelo de soja }(46 \%) \\
\text { Soybean meal }(46 \% C P)\end{array}$ & 29,5 & 27,7 \\
\hline $\begin{array}{l}\text { Óleo de soja } \\
\text { Soybean oil }\end{array}$ & 2,4 & 4 \\
\hline $\begin{array}{l}\text { Calcário } \\
\text { Limestone }\end{array}$ & 1,47 & 1,42 \\
\hline $\begin{array}{l}\text { Fosfato bicálcico } \\
\text { Dicalcium phosphate }\end{array}$ & 1,63 & 1,67 \\
\hline $\begin{array}{l}\text { Sal } \\
\text { Salt }\end{array}$ & 0,46 & 0,49 \\
\hline $\begin{array}{l}\text { Suplemento vitamínico }{ }^{2} \\
\text { Vitamin premix }\end{array}$ & 0,05 & 0,05 \\
\hline $\begin{array}{l}\text { Suplemento mineral } \\
\text { Mineral premix }\end{array}$ & 0,1 & 0,1 \\
\hline $\begin{array}{l}\text { Hidróxi-análogo de metionina }{ }^{4} \\
\text { Methionine hidroxy-analogue }\end{array}$ & 0,26 & 0,3 \\
\hline $\begin{array}{l}\text { Colina } \\
\text { Choline }\end{array}$ & 0,03 & 0,05 \\
\hline $\begin{array}{l}\text { Caulim } \\
\text { Kaolim }\end{array}$ & - & 3,1 \\
\hline
\end{tabular}

Nível nutricional

Nutritional level

\begin{tabular}{lcc}
\hline EM (kcal/kg) & 3.100 & 3.100 \\
$M E$ & 19,5 & 18,5 \\
PB (\%) & & \\
CP & 1,14 & 1,14 \\
Lys & 0,83 & 0,83 \\
Met + Cys & 1,27 & 1,20 \\
Arg & 0,75 & 0,71 \\
Thr & 0,24 & 0,23 \\
Trp & 1,11 & 1,05 \\
Relação Arg:Lis & & \\
Arg:Lys ratio & 0,95 & 0,95 \\
Ca & 0,42 & 0,42 \\
P disponível & & \\
Available P &
\end{tabular}

1 Níveis calculados segundo Rostagno et al. (2000) (Levels calculated based on Rostagno et al., 2000).

2 Suplemento vitamínico (Conteúdo por kg/ração) (Vitamin mix, content per kg/ product): Vit.A. 10.000 UI; Vit D3 3.000 UI; Vit E 60 mg; Vit K3 3 mg; Vit B1 3 mg; Vit. B2 8 mg; Vit B6 4 mg; Vit B12 0,014 mg; ácido pantotênico (pantothenic acid) 20 mg; Niacina (Niacin) 50 mg; ácido fólico (folic acid) 2 mg; biotina (biotin) $0,15 \mathrm{mg}$.

3 Suplemento mineral (Conteúdo por kg/ração) (Mineral mix, content per kg/ product): Fe 40 mg; Zn 80 mg; Mn 80 mg; Cu 10 mg; I 0,7 mg; Se 0,3 mg.

4 Bioequivalência utilizada (Used bioequivalency).

rencial dos leucócitos e a avaliação da morfologia celular foram feitas pela análise dos esfregaços sangüíneos corados, utilizando-se o corante de "Wright”. A determinação das proteínas totais, da glicose, fructosamina, albumina e hemoglobina foram feitas por técnicas fotocolorimétricas, utilizando-se kits reagentes (Labtest Diagnóstica, Brasil). Os órgãos linfóides (baço e bursa) das mesmas aves, expressos como percentual do peso vivo, foram retirados, secos em papel-toalha e pesados em balança de precisão.
As análises de variância foram realizadas pelo procedimento GLM (General Linear Models) do SAS (2001). Os blocos foram usados como variável classificatória. As comparações foram feitas dentro dos tratamentos com consumo à vontade (T1 a T4) e entre os tratamentos T2 e T4 vs T5 e T6, denominados consumo equalizado. No caso de significância, foi usado o Lsmeans para testar as diferenças entre as médias.

\section{Resultados e Discussão}

Não houve interação dos resultados de rendimento de órgãos linfóides (Tabela 2). Entre as aves com consumo à vontade, o peso relativo do bursa não foi diferente na comparação entre os dois ambientes. No entanto, o baço foi $22,5 \%$ menor para o grupo sob EPC $(\mathrm{P}<0,07)$. Nenhum dos órgãos linfóides pesados foi influenciado pelas dietas, resultados que diferem parcialmente dos verificados por Rosales et al. (1989) e Donker \& Beuving (1989), que encontraram atrofia de todos os órgãos linfóides (timo, baço e bursa de Fabrício) em aves sob EPC. Supondo-se que no calor há maior produção de corticosterona, esperar-se-ia diferença mais consistente no rendimento dos órgãos linfóides.

Entre as aves com consumo equalizado, houve influência tanto do ambiente quanto da dieta sobre o rendimento de bursa, mas não sobre o rendimento de baço. Maior rendimento de bursa foi observado nas aves mantidas no ATN e alimentadas com a dieta verão. Neste caso, a restrição alimentar não foi capaz de reduzir o peso da bursa; ao contrário, elevou-o de maneira significativa. Alguns autores afirmam que a restrição alimentar melhora a imunidade dos animais (Sibbald, 1982), exemplo claro deste fenômeno.

Os valores do eritrograma não apresentaram diferenças para o ambiente em que as aves tiveram consumo à vontade (Tabela 3). Os resultados corroboram os encontrados por Puvadolpirod \& Thaxton (2000), que, injetando o hormônio ACTH em aves, em uma simulação do que acontece no EPC, não encontraram diferenças na quantidade de células vermelhas. No caso deste experimento, o estresse cíclico por calor pode ter sido ameno a ponto de não causar desidratação, nem alterações no eritrograma dos frangos.

Nos valores hematológicos dos frangos com consumo equalizado, foi observado aumento no valor do hematócrito $(\mathrm{P}<0,03)$ dos frangos no ambiente ATN (Tabela 4). O comportamento alimentar destas aves (ração fornecida uma vez ao dia e comedouros vazios em grande parte do tempo) pode ter influenciado o padrão de ingestão de água, resultando em um quadro de desidratação e conseqüente aumento de 
Tabela 2 - Efeitos do ambiente (ATN e EPC) e da dieta (controle e verão) no peso relativo ${ }^{1}(\%)$ de bursa (RBU) e de baço (RBA) de frangos de corte aos 42 dias submetidos a dietas com consumo à vontade ou consumo equalizado

Table 2 - Effect of the environment (TN and HS) and diet (control and summer) on the relative weight ${ }^{1}(\%)$ of the bursa (RBA) in 42 day-old broilers submitted to diet with ad libitum or pair-fed intake

\begin{tabular}{|c|c|c|c|c|}
\hline \multirow[t]{2}{*}{ Item } & \multicolumn{2}{|c|}{$\begin{array}{l}\text { Consumo à vontade } \\
\text { Ad libitum intake }\end{array}$} & \multicolumn{2}{|c|}{$\begin{array}{l}\text { Consumo equalizado } \\
\text { Pair feeding intake }\end{array}$} \\
\hline & RBU (\%) & RBA (\%) & RBU (\%) & RBA (\%) \\
\hline & \multicolumn{4}{|c|}{$\begin{array}{l}\text { Ambiente } \\
\text { Environment }\end{array}$} \\
\hline $\begin{array}{l}\text { E PC } \\
\text { Heat stress }\end{array}$ & 0,186 & $0,138 b$ & $0,186 b$ & 0,138 \\
\hline A T N & 0,173 & $0,178 \mathrm{a}$ & $0,258 \mathrm{a}$ & 0,129 \\
\hline $\mathrm{P}$ & 0,63 & 0,07 & 0,005 & 0,47 \\
\hline & $\begin{array}{r}\text { Dieta } \\
\text { Diet }\end{array}$ & & & \\
\hline $\begin{array}{l}\text { Verão } \\
\text { Summer }\end{array}$ & 0,197 & 0,157 & $0,250 \mathrm{a}$ & 0,133 \\
\hline $\begin{array}{l}\text { Controle } \\
\text { Control }\end{array}$ & 0,162 & 0,158 & $0,193 b$ & 0,133 \\
\hline $\mathrm{P}$ & 0,21 & 0,97 & 0,02 & 0,99 \\
\hline CV\% & 36,8 & 32,9 & 25,05 & 22,43 \\
\hline
\end{tabular}

ATN - Ambiente termo neutro, EPC - estresse cíclico por calor (HS - cyclic heat stress, $T N$-thermoneutral environment)

${ }^{1}$ Rendimento dos órgãos em relação ao peso vivo das aves (Organs yield according to the broilers body-weight).

Médias seguidas por letras diferentes na coluna diferem (Means within a column with no common superscript differ).

hematócrito, embora a hemoglobina não tenha apresentado diferença. O tipo de dieta não influenciou os resultados de eritrograma tanto nas aves com consumo à vontade quanto naquelas com consumo restrito.

O resultado do leucograma nas aves com ração à vontade mostra interação ambiente $\times$ dieta para leucócitos totais, heterófilos e monócitos, na qual animais em EPC, alimentados com a ração verão apresentaram as menores contagens em relação aos outros tratamentos (Tabela 3). Coles (1986), Ruckebush et al. (1994) e Cunningham (1999) encontraram número elevado de leucócitos totais (leucocitose) em aves com quadro de estresse. O grupo de aves alimentadas com a ração verão no ATN, por sua vez, apresentou leucocitose significativa, acompanhada de heterofilia e monocitose, indicando algum tipo de alteração nestas aves, provavelmente em razão da maior umidade no ambiente e do maior peso corporal em relação ao outro grupo. Possivelmente, algum processo inflamatório nas patas dos frangos mais pesados do ATN, visto serem aves criadas em gaiolas metálicas, pode ter acarretado aumento de heterófilos, que são células de defesa do organismo com atividade bactericida (Harmon, 1998; Campbell, 1994 ).
No consumo equalizado, também houve efeito da interação ambiente $\times$ tipo de dieta sobre a contagem de leucócitos totais e heterófilos ( $\mathrm{P}<0,03$ e $\mathrm{P}<0,05)$ (Tabela 4), identificando-se, à semelhança de aves com consumo à vontade, efeito positivo da dieta verão para aves sob EPC.

Não foram encontradas diferenças na quantidade de eosinófilos e basófilos entre as dietas com consumo à vontade, concordando com os resultados obtidos por Scope et al. (2002). Com consumo equalizado, os eosinófilos também não apresentaram diferenças significativas, ao passo que os basófilos, nestas condições, foram maiores $(\mathrm{P}<0,01)$ no ATN que no EPC, corroborando os resultados de Maxwell et al. (1992), trabalhando com aves sob restrição alimentar. Esses autores afirmam que a basofilia em frangos pode ser indicativo de estresse severo em aves, confirmando as inferências discutidas nesta pesquisa.

A quantidade de linfócitos não apresentou diferença significativa entre EPC e ATN em nenhum dos grupos de consumo, discordando da observação de Macari \& Luquetti (2002) de que situações de estresse, nas quais ocorre a liberação de hormônio corticotrófico (ACTH), geralmente, determinam redução da quantidade de linfócitos circulantes, com o aumento da relação heterófilo:linfócito.

A relação H/L para aves sob EPC com consumo à vontade mostrou-se mais próxima das condições de normalidade, que, segundo Macari \& Luquetti (2002), está em torno de 0,5 . A interação ambiente $\times$ dieta, considerando-se uma probabilidade de $9 \%$ também se manifestou neste parâmetro, positivamente para aves sob EPC com dieta verão, indicando que estas aves sofreram menos estresse em relação aos outros grupos. A aclimatação das aves ao EPC também pode ter ocorrido, justificando a relação H/L encontrada aos 42 dias. Neste caso, a dieta verão pode ter auxiliado no processo de aclimatação, ao contrário da dieta controle.

Contrariamente, para as aves com consumo equalizado, a relação H/L foi maior nas aves no ATN, considerando-se uma probabilidade de $12 \%$, em relação àquelas sob EPC. O valor da relação H/L para as aves no ATN e EPC foi de 0,84 e 0,48 , respectivamente, ou seja, mais próximos do considerado normal, reforçando a idéia de severidade do estresse nas aves restritas. As dietas não alteraram os resultados da relação H/L.

É importante salientar a variabilidade de respostas apresentadas nas Tabelas 3 e 4, as quais sugerem que dados dessa natureza deveriam ser observados em um número expressivo de aves por tratamento.

A partir da análise bioquímica do sangue das aves com consumo de ração à vontade (Tabela 5), constata-se que não houve diferenças significativas em relação ao ambiente 
Tabela 3 - Valores hematológicos (eritrograma e leucograma) de frangos aos 42 dias submetidos a dois ambientes (ATN e EPC) e dois tipos de dieta (controle e verão) com consumo à vontade

Table 3 - Hematological values (Erythrogram e Leukogram) in 42 day-old broilers submitted two different environments (TN and HS) and two different diets (control and summer) with ad libitum intake

\begin{tabular}{|c|c|c|c|c|c|c|c|c|c|}
\hline Item & $\begin{array}{c}\mathrm{HTO} \% \\
P C V\end{array}$ & $\begin{array}{c}\mathrm{HBg} / \mathrm{L} \\
\mathrm{HB}\end{array}$ & $\begin{array}{c}\mathrm{LT} / \mathrm{mL} \\
\mathrm{TL}\end{array}$ & $\begin{array}{c}\mathrm{HET} / \mathrm{mL} \\
\text { HET }\end{array}$ & $\begin{array}{c}\mathrm{EOS} / \mathrm{mL} \\
\text { EOS }\end{array}$ & $\begin{array}{c}\mathrm{BASOF} / \mathrm{mL} \\
\text { BASO }\end{array}$ & $\begin{array}{c}\mathrm{MONO} / \mathrm{mL} \\
M O N O\end{array}$ & $\begin{array}{l}\mathrm{LINF} / \mathrm{mL} \\
L Y M P H\end{array}$ & $\begin{array}{l}\mathrm{H} / \mathrm{L} \\
\mathrm{H} / \mathrm{L}\end{array}$ \\
\hline \multicolumn{10}{|l|}{ Ambiente (Environment) } \\
\hline ATN (TN) & 31,3 & 7,4 & $22.850 \mathrm{a}$ & 11.070 & 112,9 & $1.119,6$ & 5.207 & 9.291 & 0,790 \\
\hline $\mathrm{P}$ & 0,21 & 0,65 & 0,07 & 0,04 & 0,13 & 0,18 & 0,03 & 0,74 & 0,07 \\
\hline Verão (Summer) & 30,7 & 7,6 & 18.800 & 10.868 & 30,2 & 640,1 & 4.385 & 10.018 & 0,55 \\
\hline $\mathrm{P}$ & 0,72 & 0,57 & 0,59 & 0,79 & 0,46 & 0,12 & 0,15 & 0,54 & 0,26 \\
\hline \multicolumn{10}{|l|}{ Interação (Interaction) } \\
\hline EPC $\times$ Cont $(H S \times$ control $)$ & 32,2 & 7,8 & $21.250 \mathrm{a}$ & $7.873 b$ & 60,4 & 875 & $1.732 b$ & 11.132 & $0,717 \mathrm{a}$ \\
\hline CV\% & 8,7 & 13,0 & 29,9 & 64,91 & 252,5 & 71,7 & 108,5 & 31,4 & 45,8 \\
\hline
\end{tabular}

ATN - ambiente termo neutro, EPC - estresse cíclico por calor (HS - cyclic heat stress, TN - thermoneutral environment).

Eritrograma: HTO - hematócrito; HB - hemoglobina. Leucograma: LT - leucócitos totais; HET- heterófilos; EOS - eosinófilos; BASOF - basófilos; MONO - monócitos; LINF- linfócitos; H/L - relação heterófilo/linfócito).

Erythrogram: PCV - packed cell volume; HB-hemoglobin. Leukogram:TL - total leukocytes; HET - heterophils; EOS-eosinophils; BASO - basophils; MONO - monocytes; LYMPH -lymphocytes Médias seguidas por letras diferentes na coluna diferem (Means within a column with no common superscript differ).

Tabela 4 - Valores hematológicos (eritrograma e leucograma) de frangos aos 42 dias submetidos a dois ambientes (ATN e EPC) e dois tipos de dieta (controle e verão) com consumo equalizado.

Table 4 - Hematological values (Erythrogram e Leukogram) in 42 day-old broilers submitted to two different environments (TN and HS) and two different diets (control and summer) with pair fed intake

\begin{tabular}{|c|c|c|c|c|c|c|c|c|c|}
\hline Item & $\begin{array}{c}\mathrm{HTO} \% \\
P C V\end{array}$ & $\begin{array}{c}\mathrm{HBg} / \mathrm{L} \\
H B\end{array}$ & $\begin{array}{c}\mathrm{LT} / \mathrm{mL} \\
\mathrm{TL}\end{array}$ & $\begin{array}{c}\mathrm{HET} / \mathrm{mL} \\
\text { HET }\end{array}$ & $\begin{array}{c}\mathrm{EOS} / \mathrm{mL} \\
\text { EOS }\end{array}$ & $\begin{array}{c}\mathrm{BASOF} / \mathrm{mL} \\
\text { BASO }\end{array}$ & $\begin{array}{c}\mathrm{MONO} / \mathrm{mL} \\
M O N O\end{array}$ & $\begin{array}{l}\mathrm{LINF} / \mathrm{mL} \\
L Y M P H\end{array}$ & $\begin{array}{l}\mathrm{H} / \mathrm{L} \\
H / L\end{array}$ \\
\hline \multicolumn{10}{|l|}{ Ambiente (Environment) } \\
\hline ATN (TN) & $31,6 a$ & 7,7 & 25.337 & 8.702 & 332 & $1775 a$ & 2.471 & 11.189 & 0,85 \\
\hline $\mathrm{P}$ & 0,03 & 0,8 & 0,002 & 0,05 & 0,22 & 0,01 & 0,12 & 0,31 & 0,12 \\
\hline Verão (Summer) & 30,1 & 7,7 & 18.967 & 5.827 & 117 & 1.283 & 1.411 & 10.327 & 0,6 \\
\hline $\mathrm{P}$ & 0,27 & 1 & 0,12 & 0,27 & 0,75 & 0,77 & 0,48 & 0,81 & 0,53 \\
\hline \multicolumn{10}{|l|}{ Interação (Interaction) } \\
\hline EPC x Con $(H S \times$ Control) & 31 & 7,8 & $21.250 \mathrm{a}$ & $7.873 a$ & 0 & 952 & 1.732 & 10.692 & 0,72 \\
\hline EPC x Ver (HS x Summer) & 29,2 & 7,5 & $11.700 \mathrm{~b}$ & $2.115 b$ & 0 & 405 & 2,75 & 8.904 & 0,25 \\
\hline CV\% & 5,7 & 10 & 23,5 & 53,1 & 295,6 & 61 & 104,1 & 26,2 & 68,6 \\
\hline
\end{tabular}

ATN - ambiente termo neutro, EPC - estresse cíclico por calor (HS - cyclic heat stress, TN - thermoneutral environment).

Eritrograma: HTO - hematócrito; HB - hemoglobina. Leucograma: LT - leucócitos totais; HET- heterófilos; EOS - eosinófilos; BASOF - basófilos; MONO - monócitos; LINF- linfócitos; H/L - relação heterófilo/linfócito).

Erythrogram: PCV - packed cell volume; HB-hemoglobin. Leukogram:TL - total leukocytes; HET - heterophils; EOS-eosinophils; BASO - basophils; MONO - monocytes; LYMPH - Iymphocytes Médias seguidas por letras diferentes na coluna diferem (Means within a column with no common superscript differ). 
e às dietas. Segundo González \& Silva (2003), a concentração de glicose poderia aumentar com estresse crônico. Entretanto, na situação de estresse cíclico deste experimento, não ocorreram alterações. Este achado corrobora os obtidos por Revidatti et al. (2002), que não encontraram diferenças para glicose de frangos submetidos a estresse por manejo. Segundo Puvadolpirod \& Thaxton (2000), que encontraram maiores valores de glicose em frangos injetados com hormônio ACTH, a hiperglicemia relaciona-se com quadros de estresses agudos nos quais o fator de estresse atua de forma súbita. As respostas observadas neste experimento indicam possível aclimatação das aves sob EPC (González \& Silva (2003).

Não houve diferenças significativas nos parâmetros bioquímicos do sangue de aves com ração equalizada (Tabela 6), exceto para glicose, que apresentou maior valor $(\mathrm{P}<0,02)$ para aves no ATN, indicando maior nível de estresse nas aves com restrição alimentar (González \& Silva, 2003).

No consumo à vontade, as aves no ambiente ATN apresentaram rendimento de penas (RP) 15\% maior que as aves no EPC $(\mathrm{P}<0,02)$, corroborando os achados de Cooper \& Washburn (1998), que verificaram redução significativa no empenamento de frangos de corte manti- dos em altas temperaturas $\left(32^{\circ} \mathrm{C}\right)$ (Tabela 7$)$. Os resultados também estão de acordo com Geraert et al. (1996) e Oliveira Neto et al. (2000). O menor empenamento das aves do ambiente EPC é um ajuste para facilitar a perda de calor para o meio ambiente (Geraert et al., 1996) e aumentar a temperatura crítica superior (Horst \& Mathur,1994). Por outro lado, a diminuição no consumo em altas temperaturas pode ter reduzido a quantidade de nutrientes necessários para um bom empenamento, principalmente de aminoácidos. No entanto, as diferentes dietas não influenciaram o empenamento das aves em nenhum dos ambientes.

Quando comparadas aves com consumo equalizado, não houve diferença significativa para rendimento de penas entre ambiente ou tipo de dieta. Quando se compararam aves dentro do ambiente termoneutro, observou-se que a restrição de consumo (consumo pareado) não foi suficiente para reduzir o rendimento de penas. Segundo Campo et al. (2001), aves com empenamento menor têm maior relação heterófilo:linfócito, indicando maior estresse, resultado que não se comprovou neste experimento. Tanto a restrição alimentar como o EPC são fatores de estresse e podem prejudicar o empenamento.

Tabela 5 - Parâmetros bioquímicos séricos (glicose, albumina, proteína total, globulinas e fructosamina) de frangos aos 42 dias submetidos a dois ambientes (ATN e EPC) e duas dietas (controle e verão) com consumo à vontade

Table 5 - Serum biochemical parameters (glucose, albumin, total protein, globulins and fructosamine in 42 day-old broilers submitted to two environments ( $T N$ and HS) and two diets (control and summer) ad libitum intake

Item

Parâmetro bioquímico sérico

Serum biochemical parameter

\begin{tabular}{ccccc}
\hline $\begin{array}{c}\text { Glicose }(\mathrm{mmol} / \mathrm{L}) \\
\text { Glucose }\end{array}$ & $\begin{array}{c}\text { Albumina } \\
\text { Albumin }\end{array}$ & $\begin{array}{c}\text { Proteína total }(\mathrm{g} / \mathrm{L}) \\
\text { Total protein }\end{array}$ & $\begin{array}{c}\text { Globulinas }(\mathrm{g} / \mathrm{L}) \\
\text { Globulins }\end{array}$ & $\begin{array}{c}\text { Fructosamina }(\mathrm{mmol} / \mathrm{L}) \\
\text { Fructosamine }\end{array}$ \\
\hline
\end{tabular}

Ambiente

Environment

\begin{tabular}{|c|c|c|c|c|c|}
\hline $\begin{array}{l}\text { EPC } \\
H S\end{array}$ & 12,25 & 45,5 & 16,87 & 28,75 & 1,37 \\
\hline ATN & 12,37 & 43,75 & 14,48 & 29,25 & 1,35 \\
\hline $\begin{array}{l}\text { TN-restricti } \\
\mathrm{P}\end{array}$ & 0,82 & 0,32 & 0,12 & 0,85 & 0,91 \\
\hline \multicolumn{6}{|l|}{$\begin{array}{l}\text { Dieta } \\
\text { Diet }\end{array}$} \\
\hline $\begin{array}{l}\text { Controle } \\
\text { Control }\end{array}$ & 12,25 & 43,25 & 16 & 27,5 & 1,5 \\
\hline $\begin{array}{l}\text { Verão } \\
\text { Summer }\end{array}$ & 12,37 & 46 & 15,32 & 30,5 & 1,22 \\
\hline$P$ & 0,83 & 0,13 & 0,6 & 0,27 & 0,27 \\
\hline CV \% & 8,81 & 7,63 & 19,04 & 17,86 & 37,23 \\
\hline
\end{tabular}

ATN - Ambiente termo neutro, EPC - estresse cíclico por calor (HS - cyclic heat stress, TN - thermoneutral environment). 
Tabela 6 - Parâmetros bioquímicos séricos (glicose, albumina, proteína total, globulinas e fructosamina) de frangos aos 42 dias submetidos dois ambientes (ATN e EPC), duas dietas (controle e verão) com consumo equalizado

Table 6 - Serum biochemical parameters (glucose, albumin, total protein, globulins and fructosamine) in in 42 day-old broilers submitted to two environments (TN and HS) and two diets (control and summer) with pair fed intake

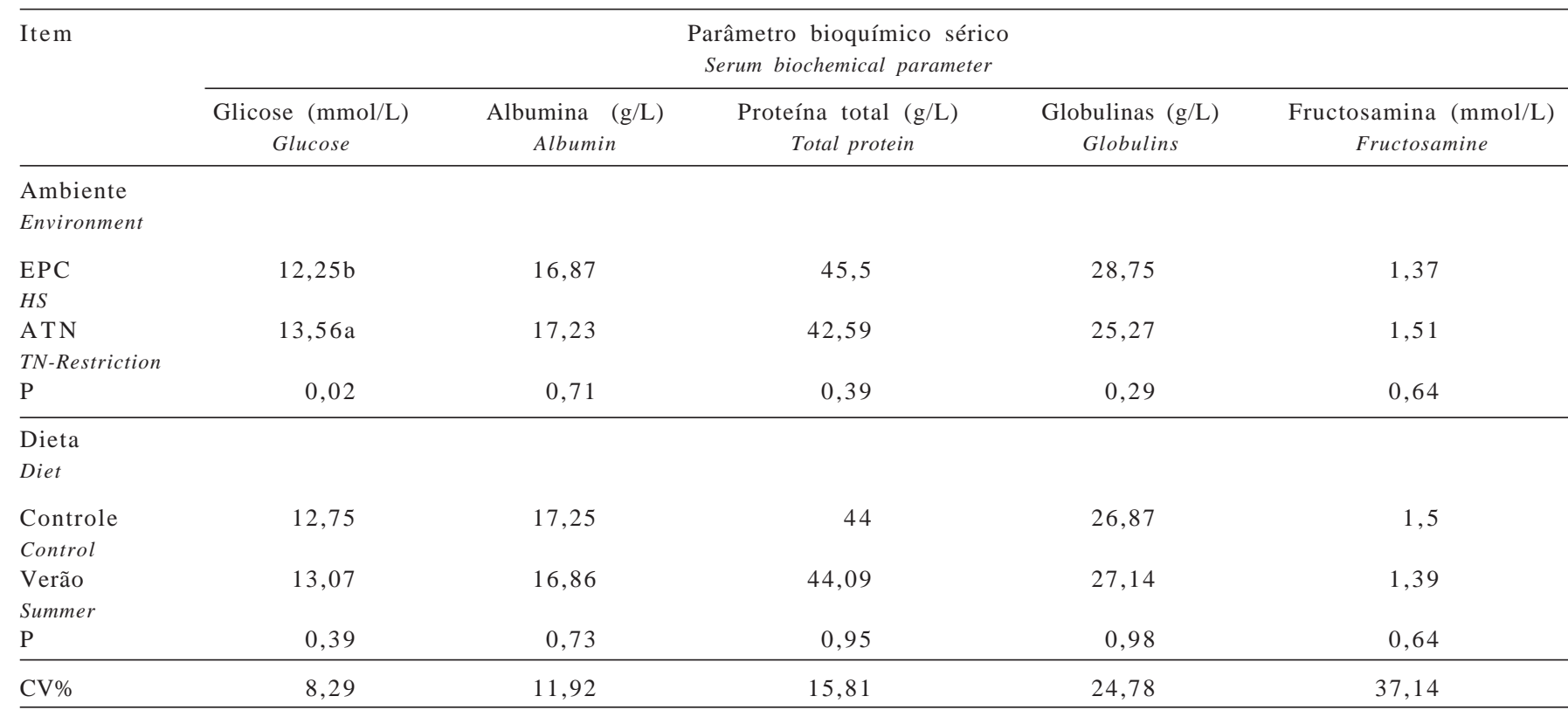

ATN - Ambiente termo neutro, EPC - estresse cíclico por calor (HS - cyclic heat stress, TN - thermoneutral environment).

Médias seguidas por letras diferentes na coluna diferem (Means within a column with no common superscript differ).

Tabela 7 - Efeito do ambiente (ATN e EPC) e do tipo de dieta (verão e controle) no rendimento de penas de frangos de corte aos 42 dias, com consumo à vontade $\mathrm{e}$ consumo equalizado

Table 7 - Effect of environmental (TN and HS) and type off diet (summer and control) on fathering of 42 day-old broilers with ad libitum feed and pair feeding intake

\begin{tabular}{lcc}
\hline \multicolumn{3}{c}{$\begin{array}{c}\text { Rendimento de penas (\%) } \\
\text { Fathering rate }\end{array}$} \\
\cline { 2 - 3 } Item & $\begin{array}{c}\text { Consumo à vontade } \\
\text { Ad libitum intake }\end{array}$ & $\begin{array}{c}\text { Consumo equalizado } \\
\text { Pair feeding intake }\end{array}$ \\
\hline Ambiente & \\
Environment & & \\
EPC (HS) & $7,29 \mathrm{~b}$ & 7,29 \\
ATN (TN) & $8,61 \mathrm{a}$ & 7,95 \\
P & 0,02 & 0,22 \\
\hline Dieta & & 7,81 \\
Diet & & 7,43 \\
Verão (Summer) & 8,21 & 0,46 \\
Controle (Control) & 7,69 & 16,50 \\
P & 0,31 & \\
\hline CV (\%) & 15,67 & \\
\hline
\end{tabular}

ATN - Ambiente termo neutro, EPC - estresse cíclico por calor (HS - cyclic heat stress, $T N$ - thermoneutral environment).

Médias seguidas por letras diferentes na coluna diferem (Means within a column with no common superscript differ).

\section{Conclusões}

A dieta verão fornecida aos animais sob estresse por calor foi capaz de amenizar alterações hematológicas e morfológicas observadas em frangos de corte submetidos ao estresse por calor e à restrição alimentar. Tanto o calor ambiental quanto a restrição alimentar foram fatores aditivos em reduzir o empenamento das aves, com ênfase no primeiro fator. O empenamento, porém, não foi influenciado pelos tipos de dieta.

\section{Literatura Citada}

BALNAVE, D.; BRAKE, J. Re-evaluation of the classical dietary arginine:lysine interaction for modern poultry diets: a review. World's Poultry Science Journal, v.58, n.4, p.275-290, 2002.

CAMPBELL, T.W. Hematology. In: RITCHIE, B.W.; HARRISON, G.J.; HARRISON, L.R. (Eds.) Avian medicine: principles and application. Fort Worth-FL: Wingers Publishing, 1994. p.177-198.

CAMPO, J.L.; GIL, M.G.; TORRES, O.; DÁVILA, S.G. Association between plumage condition and fear and stress levels in five breeds of chickens. Poultry Science, v.80, n.4, p.549-552, 2001. 
COLES, E.H. Veterinary clinical pathology. 4.ed. Philadelphia: W.B. Saunders, 1986. 486p.

COOPER, M.A.; WASHBURN, K.W. The relationship of body temperature to weight gain, feed consumption and feed utilization in broilers under heat stress. Poultry Science, v.77, n.2, p.237-242, 1998.

CUnNingham, J.G. Tratado de fisiologia veterinária. Rio de Janeiro: Guanabara, 1999. 454p.

DALE, N.M.; FULLER, H.L. Effect of diet composition on feed intake and growth of chicks under heat stress. II. Constant $x$ cycling temperatures. Poultry Science, v.59, n.9, p.14311441, 1980.

DONKER, R.A.; BEUVING, G. Effect of corticosterone infusion on plasma corticosterone concentration, antibody production, circulating leukocytes and growth in chicken lines selected for humoral immune responsiveness. British Poultry Science, v.30, n.3, p.361-369, 1989.

GERAERT, P.A.; PADILHA, J.C.F; GUILLAUMIN, S. Metabolic and endocrine changes induced by chronic heat exposure in broiler chickens: growth performance, body composition and energy retention. British Journal of Nutrition, v.75, n.2, p.195-204, 1996.

GONZÁLEZ, F.H.D.; SILVA, S.C. Introdução à bioquímica clínica veterinária. Porto Alegre: Universidade Federal do Rio Grande do Sul, 2003. 220p.

HARMON, B.G. Avian heterophils in inflammation and disease resistance. Poultry Science, v.77, n.6, p.972-977, 1998.

HORST, P.; MATHUR, P.K. Feathering and adaptation to tropical climates. In EUROPEAN POULTRY CONFERENCE, 9., 1994, Glasgow. Resumos... Glasgow: 1994. p.79-82.

MACARI, M.; LUQUETTI, B.C. Fisiologia cardiovascular. In: MACARI, M.; FURLAN, R.L.; GONZALES, E. (Eds.) Fisiologia aviária aplicada a frangos de corte. 2.ed. Jaboticabal: Universidade Estadual Paulista, 2002. p.17-36.

MAXWELL, M.H.; HOCKING, P.M.; ROBERTSON, G.W. Differential leucocyte responses to various degrees of food restriction in broilers, turkeys and ducks. British Poultry Science, v.33, n.2, p.177-187, 1992

MILLER, L.; QURESHI, M.A. Introduction of heat shock proteins and phagocytic function of chicken macrophage following in vitro heat exposure. Veterinary Immunology Immunopathology, v.37, n.1, p. 34-42, 1991.

OLIVEIRA NETO, A.R.; OLIVEIRA, R.F.M.; DONZELE, J.L. Níveis de energia metabolizável para frangos de corte no período de
22 a 42 dias de idade mantidos em ambiente termoneutro. Revista Brasileira de Zootecnia, v.29, n.4, p.1132-1140, 2000.

PEGURI, A.; COON, C. Effect of feather coverage and temperature on layer performance. Poultry Science, v.72, n.8, p.13181329, 1993.

PUVADOLPIROD, S.; THAXTON, J.P. Model of physiological stress in chickens 1. Response parameters. Poultry Science, v.79, n.4, p.363-369, 2000

REVIDATTI, F.A.; FERNANDEZ, R.J.; TERRAES, J.C. et al Modificaciones del peso corporal y indicadores de estrés en pollos parrilleros sometidos a inmovilización y volteo. Revista Veterinaria Argentina, v.12, n.1, p.11-14, 2002.

ROSALES, A.G.; VILLEGAS, P.; LUKERT, P.D. et al. Isolation, identification and pathogenicity of two field strains of infectious Bursal virus. Avian Disease, v.33, n.1, p.35-41, 1989.

ROSTAGNO, H.S.; ALBINO, L.F.T.; DONZELE, J.L. et al. Tabelas brasileiras para aves e suínos. Composição de alimentos e exigências nutricionais. Viçosa, MG: Universidade Federal de Viçosa, 2000. 141p.

RUCKEBUSH, L.P.; PHANEUF, L.P.; DUNLOP, R.F. Fisiologia de pequeñas y grandes espécies. México: Manual Moderno, 1994. 862p.

STATISTICAL ANALYSIS SYSTEM - SAS. User's guide (8.2) Cary: 2001 (CD-ROM).

SCOPE, A.; FILIP, T; GLABER, C.; RESCH, F. The influence of stress from transport and handling on hematologic and clinical chemistry blood parameters of racing pigeons (columba livia domestica). Avian Disease, v.46, n.1, p.224-229, 2002.

SIBBALD, J.D. Measurement of bioavaliable energy in poultry feeding stuffs: a review. Canadian Journal Animal Science, v.62, n.4, p.983-1048, 1982.

TEETER, R.G.; SMITH, M.O.; MURRAY, E. Force feeding methodology and equipment for poultry. Poultry Science, v.63, n.4, p.573-575, 1984.

THAXTON, J.P.; SIEGEL, H.S. Immmunodepression in young chickens by high environmental temperature. Poultry Science, v.42, n.1, p.202-205, 1982 